\title{
Nifedipine in the Treatment of Unstable Angina, Coronary Spasm and Myocardial Ischemia
}

PAUL G. HUGENHOLTZ, MD, FACC

HERMAN R. MICHELS, MD

PATRICK W. SERRUYS, MD

RON W. BROWER, PhD

Rotterdam. The Netherlands
From the Thoraxcenter, Erasmus University, Rotterdam, The Netherlands. Manuscript received April 28, 1980; revised manuscript received July 28, 1980, accepted August 14, 1980.

Address for reprints: Paul G. Hugenholtz, Thoraxcenter, Erasmus University, P.O. Box 1738 , 3000 DR Rotterdam. The Netherlands.
The effects of nifedipine, a potent calcium antagonist, were studied in pattents with unstable angina, coronary spaem and myocardial ischemia. Data from two separate groups of patients studied in the cardiac catheterization laboratory indicate that Intracoronary injectlon of nifedipine promptly reversed coronary spasm-whether provoked or spontaneous-in five of alx patients. In other patients, direct intracoronary injection of the drug was compared with intravenous administration. After intracoronary injection, local mechanical cardlac action virtually ceased, and the ventricular wall became thinner during systole. Thus, a specific inhibltory action on contractlle energy expendhure could be demonstrated in the presence of increased coronary flow. This "oxygen-sparing" effect was tested in a group of 31 patients with symptomatic unstable angina whose pain at rest, with ST-T changes, had not responded to 8 hours of treatment with maximal beta adrenergic blockade, nitrates and bed rest. The addition of $6 \times 10 \mathrm{mg}$ of nifedipine rendered 27 of these patients asymptomatic within 1.5 hours. In the four patients who did not respond, coronary arteriography demonstrated severely stenotic lesions. Two of the four patients subsequently responded to intrasortic balioon pumping and bypass surgery; one patient had a myocardial infarction and one who had a 90 percent reduction in the dlameter of the left main coronary artery, died.

It is concluded that nifedipine should be added to beta adrenergic blockade therapy if the latter does not appear to be immediately effectlve. This comblnation has not been shown to cause any hemodynamic deterioration, and only a minority of the patients treated sustained a myocardial infarction during the first 3 months of follow-up. The use of nlfedipine in unstable angina deserves further clinical evaluation.

The concept that coronary vasospasm is one cause of angina pectoris and myocardial infarction has recently been rediscovered, almost a century after the original descriptions by Latham. ${ }^{I}$ In fact, in the past few years, several investigators ${ }^{2-7}$ have brought about a shift in attitude concerning the pathophysiologic derangements underlying myocardial infarction. It is now accepted that temporary obliteration of coronary blood flow due to increased vessel wall tone, even in the absence of fixed coronary arterial obstruction and stenosis, can lead to myocardial infarction. Most likely, intermittent and fixed coronary stenosis act in combination; that is, increased vasomotility of a major vessel around a fixed obstruction causes the critical reduction in flow that leads to irreversible ischemia. To what extent platelet aggregates and disturbances in prostaglandin metabolism play a role is as yet unclear, but their effects may well be additive.

Such a view opens new avenues for treatment because, if coronary spasm or increased vascular tone can be recognized, timely relief of the condition should reverse the process of impending infarction. Our cur- 


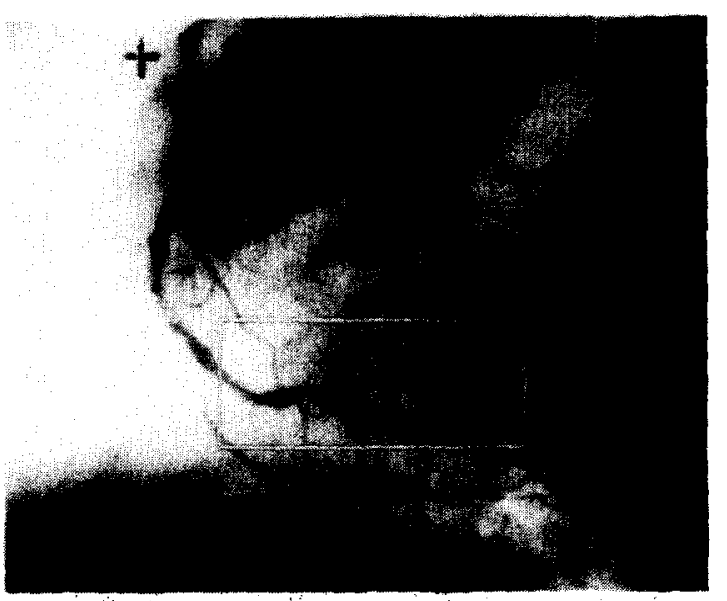

BEFORE INTERVENTION
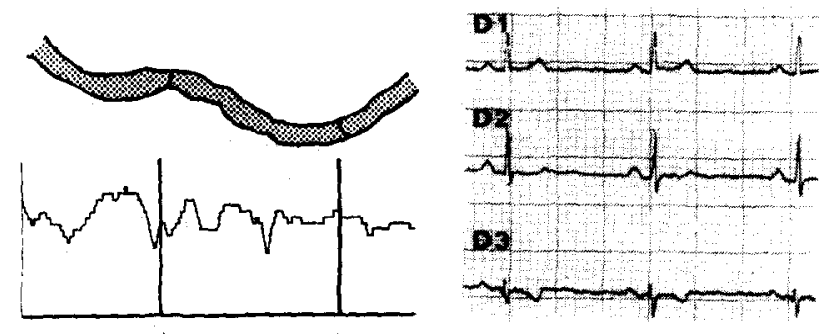

mean diameter 15.8 units

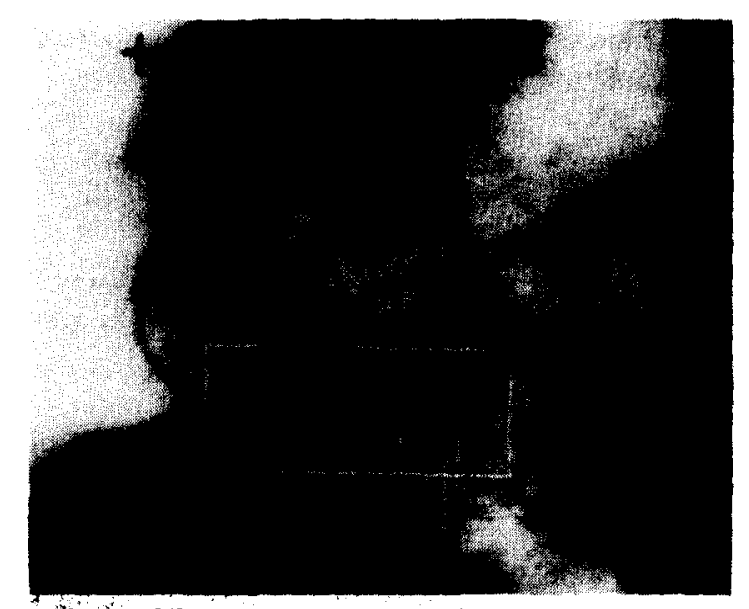

$1 \mathrm{~min}$ After $0.4 \mathrm{mg}$ Methergine I.V.
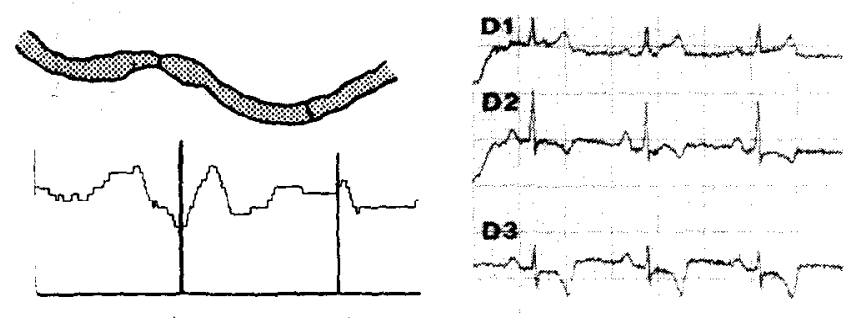

mean diameter 14.8 units

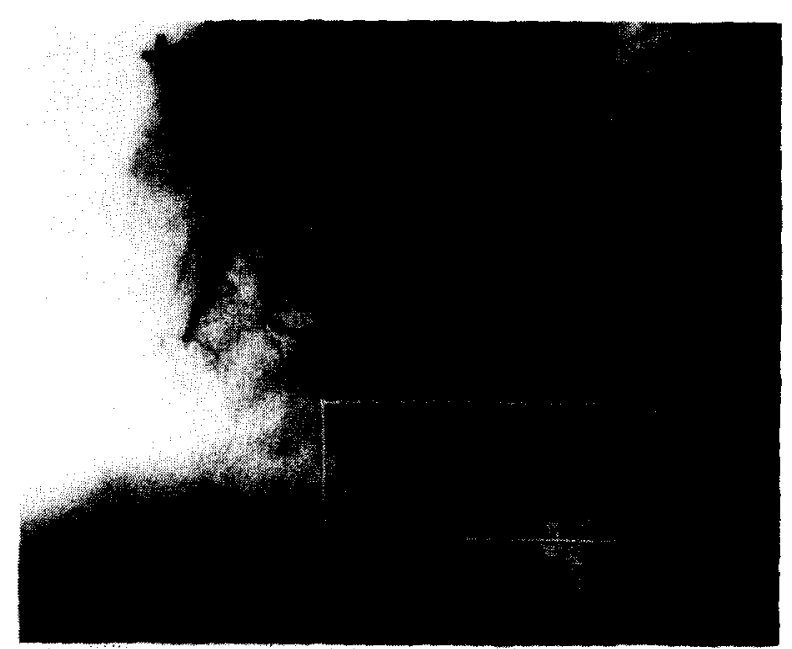

$3 \mathrm{~min}$ AFTER $0.4 \mathrm{mg}$ METHERGINE I.V.
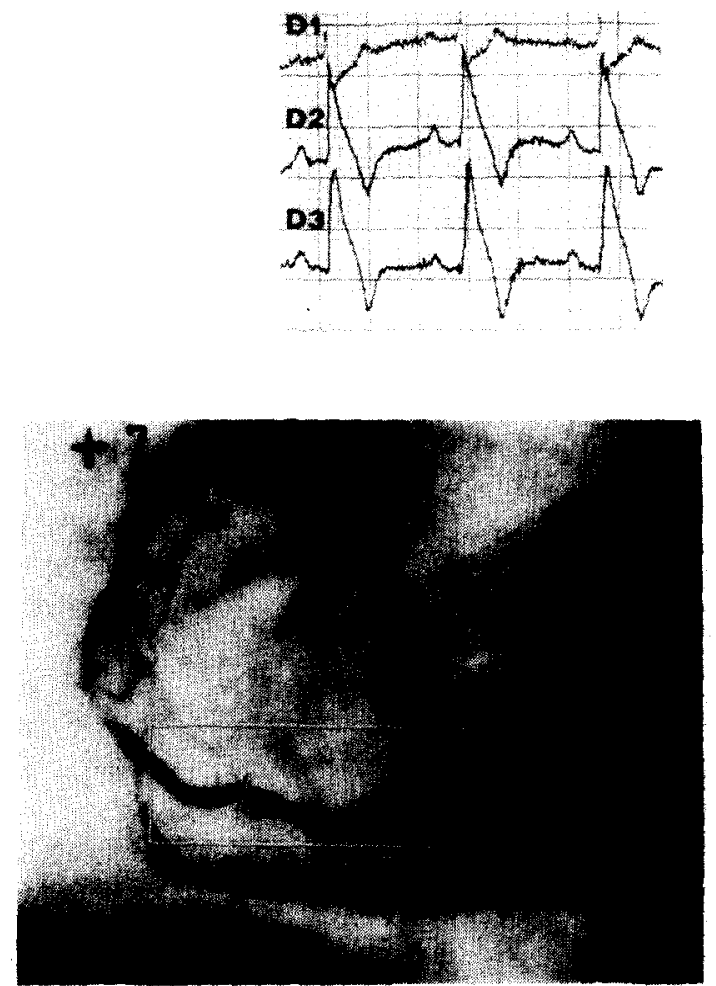

$1 \mathrm{~min}$ AFTER $0.2 \mathrm{mg}$ NIFEDIPINE I.C.
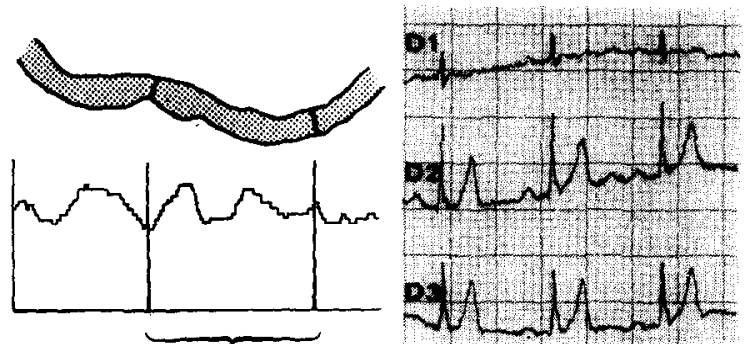

mean diameter $\mathbf{2 1 . 5}$ units

FlaURE 1. Patient I (Table l). Four frames from a cineangiogram. Upper left, the involved right coronary artery before intervention. Lower loft and upper right spasm provoked by an intravenous (I.V.) injection of methergine (ergonovine). Note that in the upper right frame the artery has virtually "disappeared". Lower right, abolition of the spasm by intracoronary (I.C.), injection of nifedipine. Simultaneously recorded electrocardiograms (leads I, II and III) are shown. An automated measurement system was employed to grade changes in the caliber of the right coronary artery (bottom) which is expressed in units reflecting a surface area. ${ }^{16}$ 
rent study relates to several experiences that provide a partial answer to the potential efficacy of nifedipine in this scheme of events. First, nifedipine's powerful action as a calcium antagonist leads to vessel dilation, which has proved effective in classic Prinzmetal's angina in which spasm is known to be the main causative mechanism. Direct intracoronary injection of nifedipine has been observed to lead to prompt restoration of the normal caliber of a totally occluded vessel.

However, other actions of nifedipine may make this drug equally attractive for the treatment of patients with unstable angina pectoris. In our laboratory, measurements of left ventricular function, both in pigs and in human subjects, have shown that local mechanical contraction ceases for up to 5 minutes when nifedipine is injected into the coronary artery supplying the ischemic cardiac muscle. In patients with unstable angina, the best protective action for ischemic cells might be provided if coronary flow could be increased and local consumption of oxygen simultaneously decreased, while electrical activation continued normally.

To test these hypotheses, we studied a group of patients admitted to the coronary care unit with angina pectoris at rest and transient $\mathrm{S}-\mathrm{T}$ segment or $\mathrm{T}$ wave changes but without evidence of acute myocardial infarction, such as abnormal enzyme release and development of $Q$ waves. At our center, this high risk group of patients with unstable angina is routinely managed with bed rest and administration of oxygen, sedatives, long-acting nitrates and beta adrenergic blocking agents. The therapeutic objective is to return the patient with signs of myocardial ischemia to a stable and asymptomatic state, thereby preventing infarction. In our hands, this regimen has not proved successful in all patients. In fact, until recently it was our policy to proceed to emergency coronary bypass surgery (in several cases with prior intraaortic balloon pumping) when no relief was obtained after 8 to 12 hours of maximal therapy with beta adrenergic blocking agents. ${ }^{8}$

\section{Study 1}

\section{Methods}

The methodology employed for the animal data quoted under Results has been published elsewhere and will not be repeated here.

For the first part of the clinical study, data were collected from 6 patients who underwent cardiac catheterization because of myocardial ischemia suspected to be secondary to spasm and from 10 other patients who have had bypass surgery 1 year before catheterization. In the latter group, a total of 26 pairs of radiopaque platinum markers had been implanted on the epicardium at operation. Seventeen of these marker pairs (in 10 patients) were placed on areas newly supplied by blood from the coronary arterial bypass graft, and nine pairs of markers (in 9 patients) were placed in areas not supplied by the coronary arterial system.

Patients with coronary spasm: Of the six patients with suspected coronary arterial spasm, two showed the fullfledged clinical syndrome of Prinzmetal's angina. During catheterization, spontaneous spasm was observed in three of the six, and in another two spasm was induced by intravenous injection of methergine (an ergot alkaloid similar to ergono- vine). In the sixth patient, spasm was induced during manipulation of the catheter. In each patient, as soon as spasm was observed, the average dose of nifedipine $(2 \mu \mathrm{g} / \mathrm{kg}$ body weight) was selectively injected into the coronary artery in spasm and biplane filming was performed (Fig. 1, Table I). This average dose had been selected as a result of previous studies in our laboratory. ${ }^{9}$ No effort was made to test the patient's response to nitrates before administration of nifedipine.

Patients after coronary bypass surgery: During recatheterization of 10 postoperative patients a pacing catheter was placed into the right atrium (Fig. 2). Heart rate was fixed at 10 beats above the spontaneous rate present before the pharmacologic intervention. Left ventricular pressures were recorded with a double micromanometer (Millar PC770 or 780). The methodology for measuring regional shortening from epicardial radiopaque markers has been described in detail elsewhere. ${ }^{10}$ In brief, the radiopaque marker pairs implanted in the epicardium at operation are filmed during synchronized biplane cinefluoroscopy at 50 frames/s. The absolute distances between each marker pair are calculated, with five consecutive heart beats being analyzed as a control set before intrabypass injection of nifedipine and again 30,60 , 120 and 180 seconds after the injection. During this period, variables derived from left ventricular pressure measurements are monitored continuously by means of the beat to beat analysis program of our cardiac catheterization laboratory computer. ${ }^{11}$ Pressures were recorded for a period of 5 minutes before and during the injection of nifedipine. End-diastolic pressure, peak systolic pressure, peak positive first derivative of left ventricular pressure $(\mathrm{dP} / \mathrm{dt})$, cycle length, peak velocity of contractile elements $\left(V_{c e)}\right.$ and maximal velocity of contractile elements $\left(V_{\max }\right)$ were derived by means of the on-line computer program. In addition, an analysis of the isovolumic relaxation phase was carried out by calculating the peak negative $\mathrm{dP} / \mathrm{dt}$. The relaxation time constant was determined by a least-squares fit of a monoexponential equation describing the fall of left ventricular pressure from the moment

\section{TABLE I}

Arteriographic Findings and Effect of Nifedipine in S1x Patients Whth Elther Spontaneous or Induced Coronary Arterial Spasm

\begin{tabular}{|c|c|c|c|c|}
\hline Case & Spasm & $\begin{array}{l}\text { Arteriographic } \\
\text { Findings } \\
\text { (vessel and } \\
\% \text { obstruction) }\end{array}$ & $\begin{array}{l}\text { Intracoronary } \\
\text { Nifedipine* }\end{array}$ & $\begin{array}{l}\text { Intravenous } \\
\text { Nitroglycerin }\end{array}$ \\
\hline 1 & $\begin{array}{l}\text { Methergine- } \\
\text { induced }\end{array}$ & $\begin{array}{c}\text { RCA } \\
(100 \%)\end{array}$ & + & $\cdots$ \\
\hline 2 & $\begin{array}{l}\text { Methergine- } \\
\text { induced }\end{array}$ & $\begin{array}{c}\text { LCX } \\
(100 \%)\end{array}$ & - & + \\
\hline 3 & Spontaneous & $\begin{array}{c}\text { RCA } \\
(75 \%)\end{array}$ & + & $\cdots$ \\
\hline 4 & Spontaneous & $\begin{array}{l}\text { LAD } \\
(75 \%)\end{array}$ & + & $\cdots$ \\
\hline 5 & $\begin{array}{l}\text { Catheter- } \\
\text { Induced }\end{array}$ & $\begin{array}{c}\mathrm{RCA} \\
(75 \%)\end{array}$ & + & $\cdots$ \\
\hline 6 & Spontaneous & $\begin{array}{c}\text { LCX } \\
(100 \%)\end{array}$ & + & $\cdots$ \\
\hline
\end{tabular}

- Immediate administration of intracoronary nifedipine relieved the obstruction completely in five of six patients; intravenous nitroglycerin proved effective in one.

$\mathrm{LAD}=$ left anterior descending coronary artery; $\mathrm{LCx}=$ left circumflex coronary artery; $\mathrm{RCA}=$ right coronary artery; $+=$ effective; $-=$ not effective; ... = not administered. 


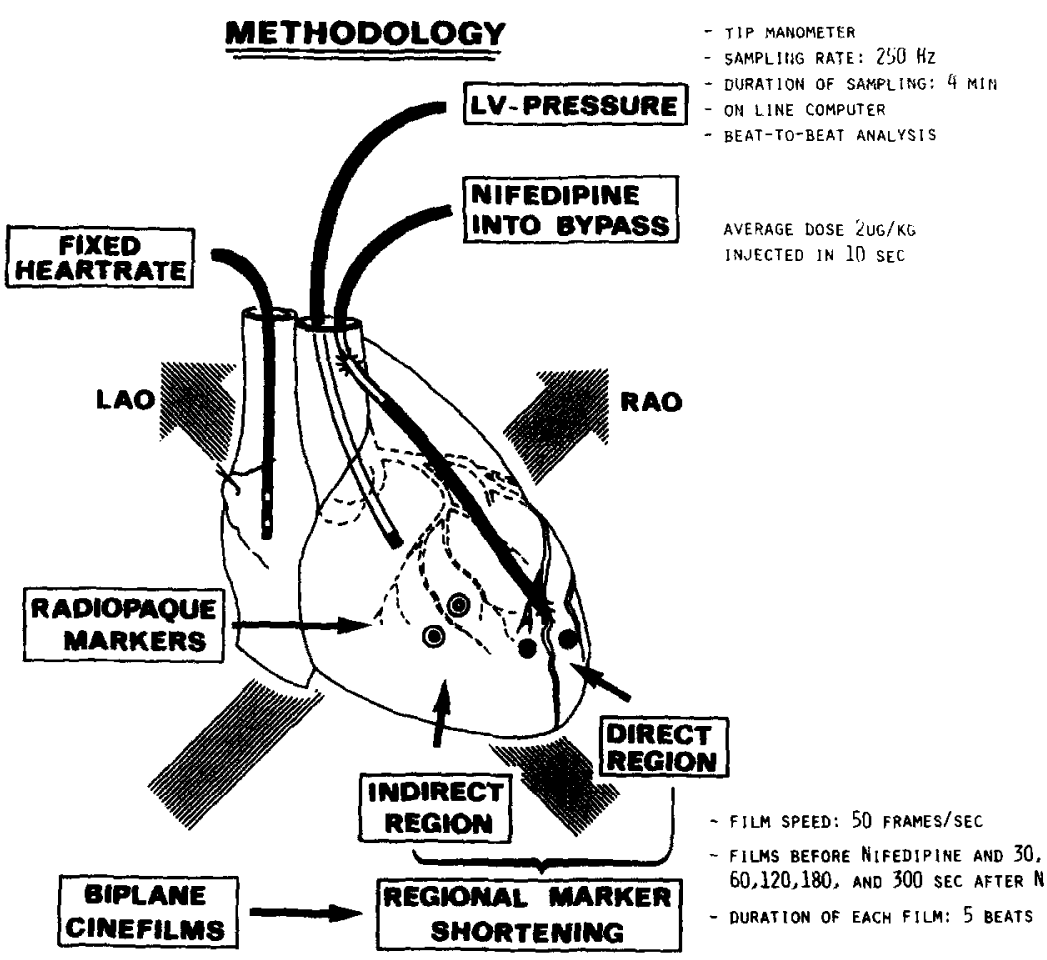

FIGURE 2. Diagram of the principal methods employed in the study. See text and Reference 10 for details on the measurement of regional shortening with radiopaque markers attached to the epicardium during coronary bypass surgery. $L A O=$ left anterior oblique; $L V=$ left ventricular; $\mathbf{N}$. = nifedipine; RAO = right anterior oblique. of peak negative $\mathrm{dP} / \mathrm{dt}$ to that existing at a pressure of $35 \mathrm{~mm}$ Hg (Fig. 3).

\section{Study 2}

Patients with unstable angina: The second part of the study, was carried out between June 1, 1979 and January 1, 1980, when 720 patients with various symptoms of coronary artery disease were admitted to our coronary care unit. Forty-seven of these patients had precordial pain at rest that was typical of angina pectoris and that persisted or worsened. In all 47 patients, transient ST-T changes but no new $Q$ wave formation were documented in the coronary care unit during angina at rest. The patients' serum enzyme levels were often elevated but in no instance reached values twice the normal in our laboratory.

On admission, all patients were placed in a private room, although they remained directly accessible to the nursing staff. Hemodynamic monitoring was initiated immediately by means of a Swan-Ganz thermodilution catheter advanced from the subclavian or right jugular vein or an arm vein into the pulmonary artery. If either hypotension or hypertension was present initially, a catheter was inserted into the left radial artery with use of local anesthesia. All patients received heparin intravenously (30,000 units or less every 24 hours). A semiautomated monitoring system facilitated continuous recording of heart rate, cardiac rhythm and pul-

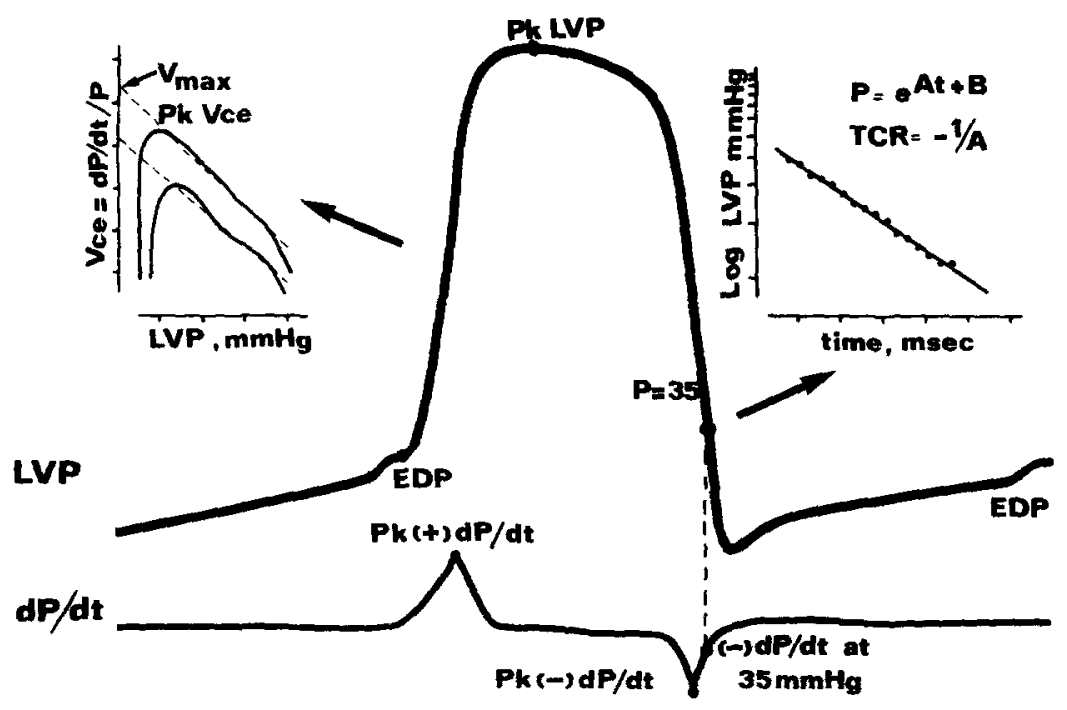

FICURE 3. Isovolumic variables, as determined by the beat to beat analysis program of the catheterization laboratory computer system. $\mathrm{dP} / \mathrm{dt}=$ rate of rise of left ventricular pressure; EDP = end-diastolic pressure; LVP $=$ left ventricular pressure; $P=35=$ pressure at $35 \mathrm{~mm}$ $\mathrm{Hg} ; P=e^{A T}+B=$ the constant and intercept of the regression line; $P K=$ peak: TCR $=$ time constant for $r \theta-$ laxation determined by slope (A) of pressure on log-linear plot; $V_{c e}=$ velocity of contractile elements; $V_{\max }=$ maximal velocity of contractile elements. 
monary arterial pressure, while systemic blood pressure and cardiac output were determined at regular intervals. During and after every attack of pain, a 12 lead electrocardiogram was recorded, and if pain persisted, the recording was repeated at 15 minute intervals. On admission and 6 hours after each attack of pain, creatine kinase, MB-creatine kinase and $\alpha$-HBDH cardiac enzymes were measured.

After initial sedation, usually with oral diazepam (5 to $10 \mathrm{mg}$ three times daily), the patient was given isosorbide dinitrate, $5 \mathrm{mg}$ every 2 hours sublingually or, if necessary, intravenously. In addition, propranolol was administered intravenously at doses ranging from 1 to $10 \mathrm{mg}$ until a heart rate of 60 beats $/ \mathrm{min}$ was reached. Thereafter, propranolol was given orally at doses ranging from 400 to $800 \mathrm{mg}$ every 24 hours. When propranolol was contraindicated, as in patients with lung disease, a cardioselective beta adrenergic blocking agent was chosen.

The 47 patients studied included 38 men and 9 women aged 29 to 77 years (mean 58 ). Three subgroups of patients could be identified: Twelve (group I) had no history of previous coronary artery disease, 25 (group II) had a history of long-standing coronary artery disease and the remaining 10 (group III) had a return of angina at rest within 2 weeks after discharge from the hospital where they had been treated for an acute myocardial infarction. Two patients in group II and one in group III had previously had coronary bypass grafting.

\section{Results}

Nifedipine injection into coronary bypass graft: Data collected from the patients studied during cardiac catheterization are shown in Tables I and II and Figures 4 and $5 .{ }^{12}$ After direct injection of nifedipine into the coronary graft bypass the expected reduction in peak left ventricular systolic pressure occurred. There was also an increase in end-diastolic pressure as well as a marked decrease in peak positive $\mathrm{dP} / \mathrm{dt}$, peak negative $\mathrm{dP} / \mathrm{dt}$ and $\mathrm{V}_{\max }$, and an increase in the relaxation time constant. All of these differences were statistically significant when compared with control measurements.

\section{TABLE ||}

Pressure-Derived Varlables After Intracoronary Bypass Injection of Nlfedipine (10 injections, mean \pm standard error of the mean)

\begin{tabular}{lcr}
\hline & $\begin{array}{c}\text { Control } \\
\text { Value }\end{array}$ & Peak Effect \\
\hline Peak LVP $(\mathrm{mm} \mathrm{Hg})$ & $141 \pm 8$ & $124 \pm 7^{\circ}$ \\
EDP $(\mathrm{mm} \mathrm{Hg})$ & $16 \pm 2$ & $26 \pm 3^{\circ}$ \\
Peak positive $\mathrm{dP} / \mathrm{dt}(\mathrm{mm} \mathrm{Hg} / \mathrm{s})$ & $1855 \pm 118$ & $1521 \pm 73^{\dagger}$ \\
$V_{\text {max }}($ lengths $/ \mathrm{s})$ & $55 \pm 3$ & $43 \pm 2^{\circ}$ \\
Peak negative dP/ct $(\mathrm{mm} \mathrm{Hg} / \mathrm{s})$ & $2133 \pm 135$ & $1575 \pm 86^{\circ}$ \\
Negative dP/dt at $35 \mathrm{~mm} \mathrm{Hg}(\mathrm{mm} \mathrm{Hg} / \mathrm{s})$ & $873 \pm 43$ & $598 \pm 53^{\circ}$ \\
Relaxation time constant (lengths/s) & $39 \pm 2$ & $54 \pm 3^{\circ}$ \\
\hline
\end{tabular}

- $p<10^{-5}{ }^{\dagger} p<10^{-4}$.

$\mathrm{dP} / \mathrm{dt}=$ rate of change of left ventricular pressure; $E D P=$ end-diastolic pressure; $L V P=$ left ventricular pressure; $V_{\max }=$ maximal velocity of contractile elements.

The shortening fraction during ejection, that is, the systolic phase of the cardiac cycle, was markedly decreased in the area directly perfused by the artery into which nifedipine had been injected (Fig. 4 and 5); in contrast, no changes were observed elsewhere in the heart. The onset of regional shortening was delayed and the shortening rate was diminished. Minimal length was shifted from end-systole to early diastole, as if contraction had continued during diastole.

These responses were previously observed in experimental animals in which regional wall thickness and blood flow in the left anterior descending coronary artery were measured in areas perfused by this artery after nifedipine was injected directly into it (Fig. 6A). ${ }^{9}$ The difference between coronary arterial and pulmonary arterial infusion is shown in Figure 6. All changes in left ventricular variables were transient, and function returned to control levels within 5 minutes. All measurements were made at a constant rate of pacing, and direct slowing of contraction and relaxation must be inferred.

Oral nifedipine in unstable angina (Fig. 7): Sixteen of the 47 patients with unstable angina who were treated with propranolol or other beta blocking agents

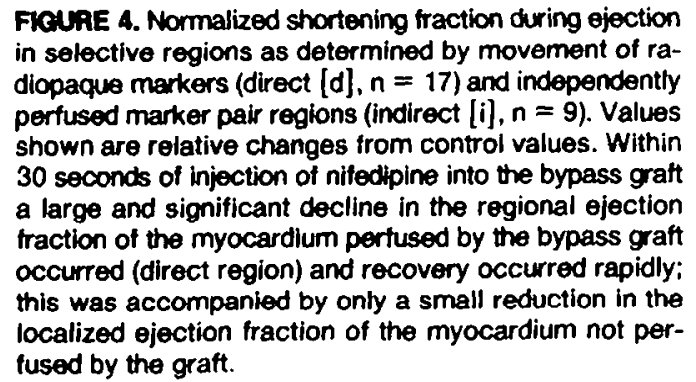

FICUAE 4. Normalized shortening fraction during ejection diopaque markers (direct [d], $n=17$ ) and independently perfused marker pair regions (indirect [i], $n=9$ ). Values shown are relative changes from control values. Within 30 seconds of injection of nifedipine into the bypass graft a large and significant decline in the regional ejection fraction of the myocardium perfused by the bypass graft this was accion localized ejection fraction of the myocardium not perfused by the graft.

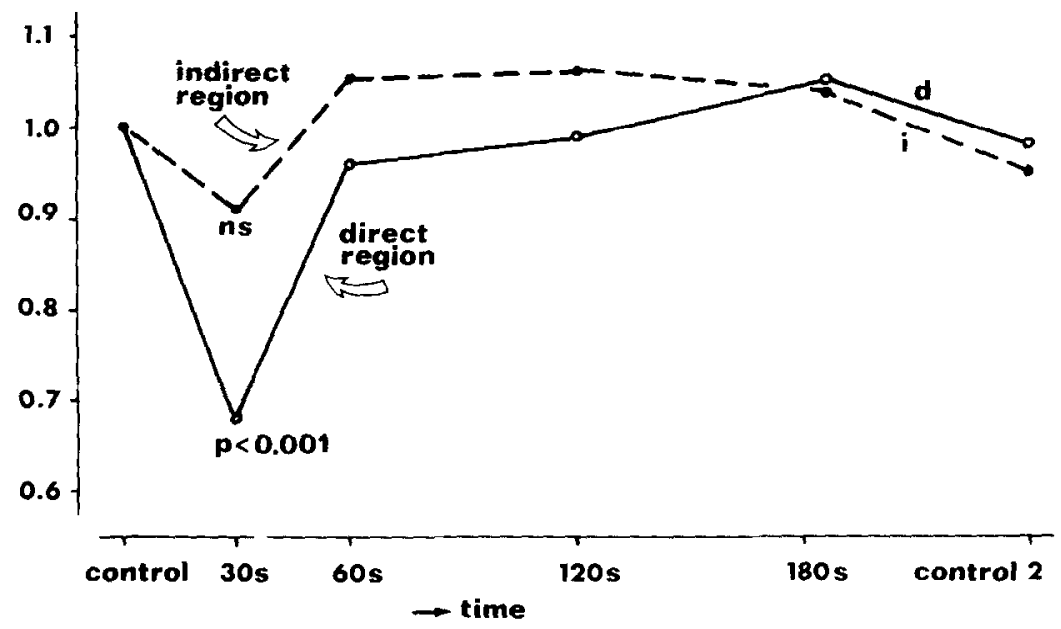



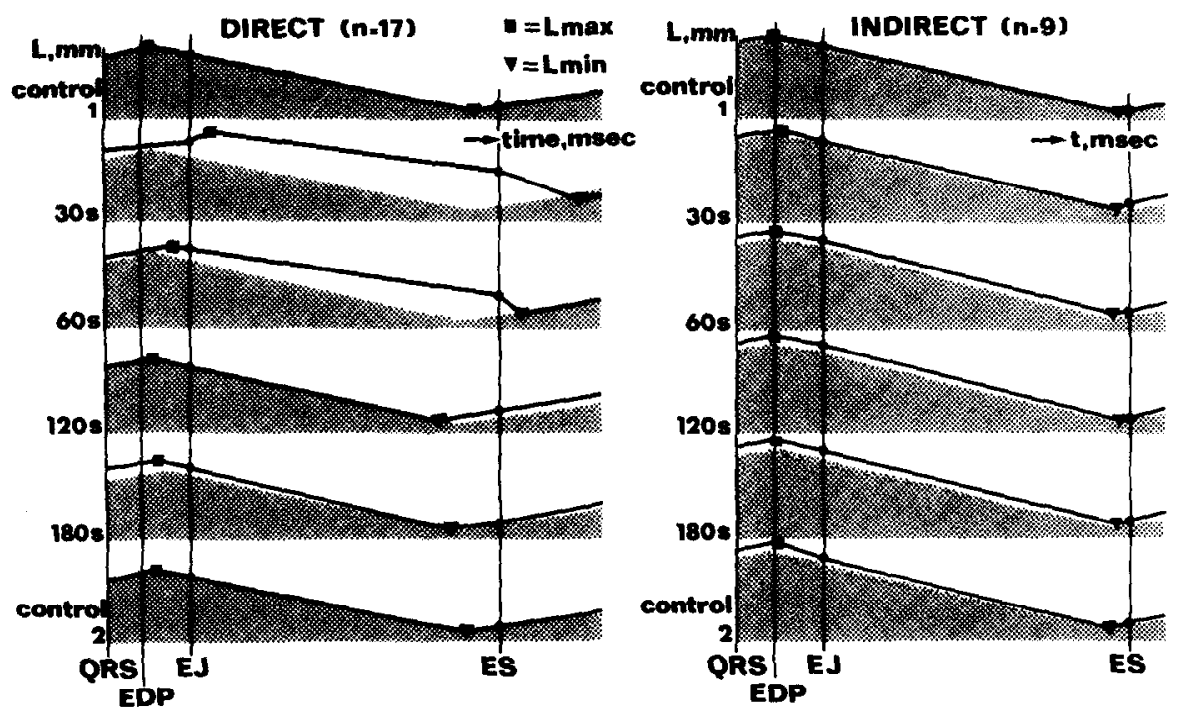

FICURE 5. Regional shortening measured with pairs of radiopaque markers in (left) region of myocardium into which nifedipine had been injected (direct, $n=17$ ) and (right) other regions of myocardium (indirect, $n=9$ ). From top to bottom: Control period and 30,60, 120 , and 180 seconds after intrabypass injection of nifedipine. The shaded area represents the shortening pattern of the first control period. In selectively injected regions, the onset of regional shortening ( $\left.L_{\max }\right)$ is delayed, the shortening rate is diminished, and $L_{m i n}$ is shifted from end-systole to early diastole. EDP = end-diastolic pressure; $E \mathrm{~J}=$ ejection; $\mathrm{ES}=$ end-systole. Lett panel reproduced from Serruys et al. ${ }^{12}$ by permission of the American Heart Association, Inc. and nitrates became asymptomatic 3 to 8 hours after the onset of treatment. Of the other 31 patients who, in addition, received oral nifedipine in doses of $10 \mathrm{mg}$ six times a day, 27 became asymptomatic within 1.5 hours and remained so for the remainder of their hospital stay; 4 patients did not respond to nifedipine. Two of these sustained a myocardial infarction within 24 hours, and one died. Because of persistent pain, two other patients underwent intraaortic balloon pumping, with immediate relief of symptoms. ${ }^{8}$ Both underwent coronary bypass grafting and both are alive. Coronary arteriography showed that three of these four patients had more than 75 percent obstruction in three vessels, while the fourth patient, a 73 year old man, had 90 percent obstruction of the left main coronary artery and had a fatal myocardial infarction shortly after coronary arteriography.

Twenty of the 27 patients who experienced initial relief of symptoms when nifedipine was added to the therapeutic regimen underwent elective coronary arteriography and left heart catheterization after they resumed some degree of physical activity in the intermediate care unit. However, one patient with postinfarction angina (group III) sustained a fatal myocardial infarction before catheterization and within 7 days of initiation of nifedipine treatment. Of the 19 patients undergoing catheterization, 1 had greater than 90 percent cross-sectional obstruction of the left main coronary artery and 9 had three vessel, 3 had two vessel and six had one vessel coronary artery disease with greater than 75 percent obstruction.

Follow-up: In addition to the patient with fatal infarction, four other patients had a nonfatal infarction within 2 weeks after the initial relief of symptoms. In two of these patients, the event was related to angiography; both had extensive pain, with ST-T changes and a slight rise in cardiac enzyme levels but without new $Q$ wave formation. In one of the other two patients coronary arterial spasm was documented during angi- ography and injection of nifedipine into the involved coronary artery led to immediate relief.

Thus, of the total group of 27 patients who were managed with nifedipine and who became asymptomatic, 5 sustained an infarction (fatal in 1 ) within 2 weeks after initial stabilization. During further follow-up (3 to 5 months) no other instances of myocardial infarction were noted. Thus far, 15 of the 19 patients who underwent catheterization have undergone elective coronary bypass grafting. In these patients, the indication for operation consisted of a past history of unstable angina and an advanced degree of coronary arterial stenosis. All are alive and well. The other 11 patients have remained asymptomatic and have been maintained on nifedipine therapy.

\section{Discussion}

Effect of nifedipine on coronary spasm and on myocardial contraction (local contractile arrest in presence of increased coronary flow): The two parts of this study were carried out in patients with proved or suspected coronary arterial spasm. From the data in Table I, there is little doubt that in the majority of patients, direct intracoronary injection of nifedipine yields prompt relief when spasm can be demonstrated. Other authors, ${ }^{2-6}$ using a variety of techniques, have demonstrated that this calcium blocking agent has a similar beneficial action. In addition, the data shown in Figures 4,5 , and 8 indicate that locally administered nifedipine acts directly on the myocardium. Measurements of the changing distances between radiopaque markers placed on the epicardium (Fig. 5) indicate that major changes in wall motion take place as early as 30 seconds after injection of nifedipine. The distance between the markers is substantially increased, with a reduction in regional shortening to approximately 67 percent of the control value. The rate of systolic shortening is significantly diminished, indicating a slowing of the local contractile process; the separation between the marker 


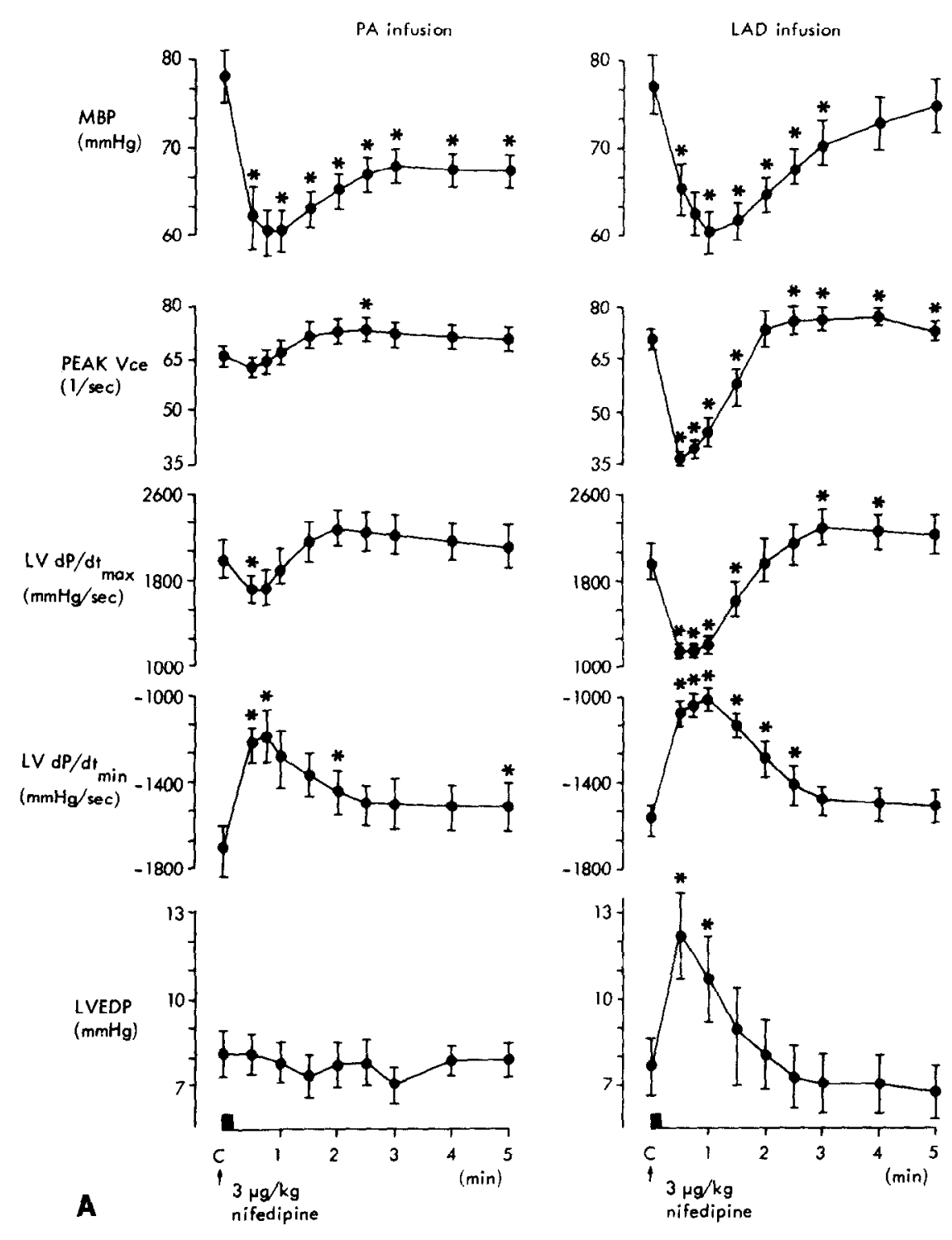

FIGURE 6. A, Hemodynamic changes after administration of $3 \mu \mathrm{g} / \mathrm{kg}$ of nifedipine into the pulmonary artery (PA) and into the left anterior descending coronary artery (LAD) of the same pig. Note that the effects on mean arterial blood pressure (MBP) and the rate of fall of left ventricular pressure ( $\mathrm{LV} \mathrm{dP} / \mathrm{dt}_{\mathrm{min}}$ ) are independent of the site of injection, whereas the magnitude of the effects on myocardial contractility (peak $V_{c e}$ and LV dP/dt max $_{\text {max }}$ and ventricular filling pressure (LVEDP) are dependent on the site of the injection. The heart was paced at 104 beats $/ \mathrm{min}$. $P<0.05$ compared with baseline. B, left anterior descending coronary arterial (LAD) blood flow (from an electromagnetic flowmeter) and myocardial wall thickness after administration of $3 \mu \mathrm{g} / \mathrm{kg}$ of nifedipine into the pulmonary artery (PA) and the left anterior descending coronary artery. Injection into the pulmonary artery had no effect, that into the left anterior decending artery caused a transient decrease, mainly in end-systolic thickness (EST). After 3 minutes, a rebound in end-diastolic thickness (EDT) was observed $(0.5 \mathrm{~mm}$ larger than baseline value). " $p<0.05$ compared with baseline value.
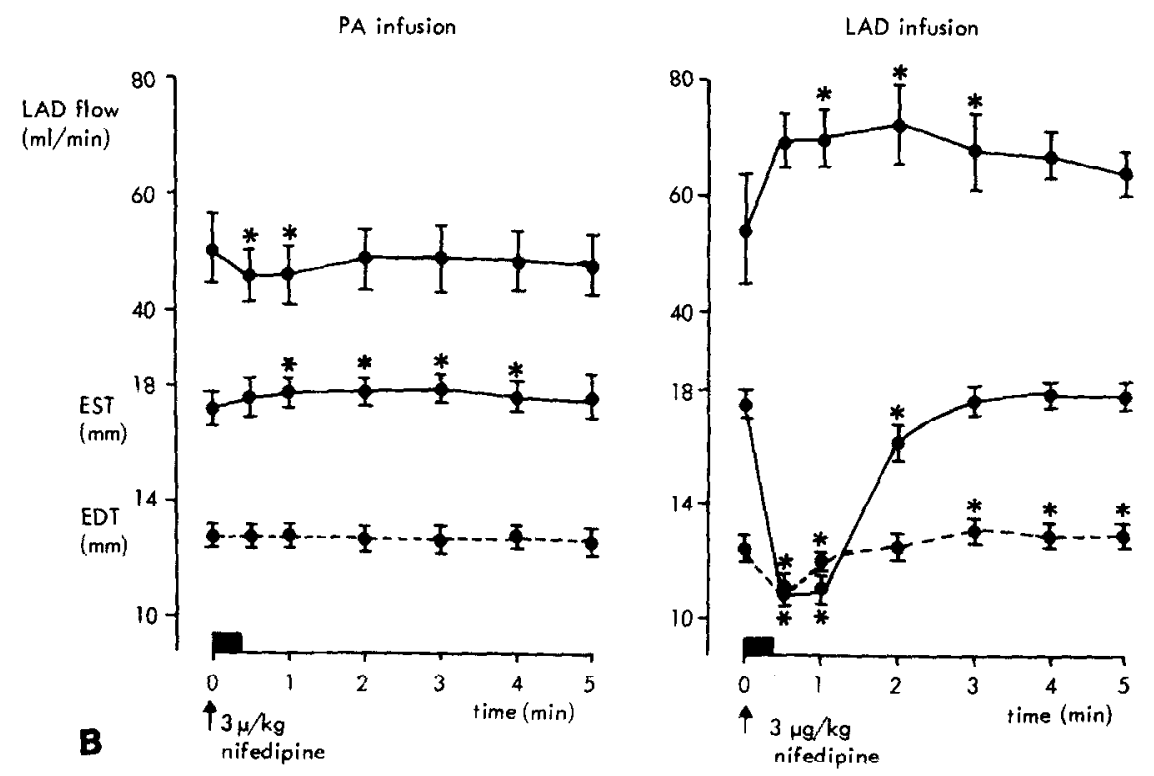

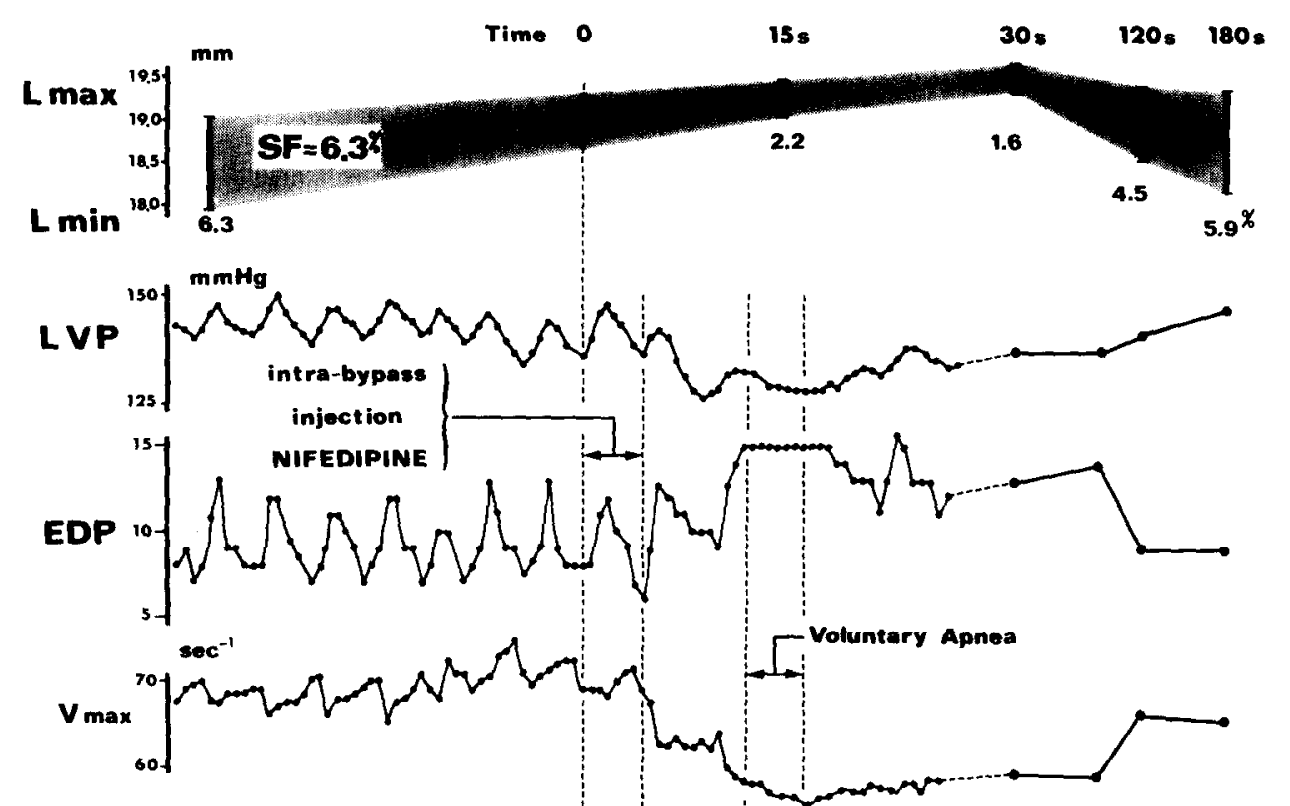

FIGURE 7. Continuous plot of marker distance $\left(L_{\max }, L_{\min }\right)$ with shortening fraction, left ventricular pressures (LVP and EDP), $V_{\text {max }}$ and the relaxation time constant of the region perfused by an injection of nifedipine into a patent bypass graft. In this patient, coronary sinus flow was measured continuously. Shortly after intrabypass injection of nifedipine, the shortening fraction (SF) decreased from 6.3 to 2.2 percent, accompanied by a rapid rise in end-diastolic pressure and decreases in $V_{\max }$ and left ventricular peak pressure. Simultaneously coronary sinus flow increased from 150 to more than $200 \mathrm{ml} / \mathrm{min}$.

pairs reaches a minimum $80 \mathrm{~ms}$ after closure of the aortic valve, indicating that contraction became prolonged; in fact, at the peak of action of nifedipine, 38 percent of total regional shortening took place during early diastole of the ventricle as a whole. None of these changes were seen when marker distances were measured in the same patient in areas not perfused by nifedipine.

These observations complement published results from studies performed in our laboratory in the open chest pig $^{9}$ when nifedipine, in a dose of $3 \mu \mathrm{g} / \mathrm{kg}$, was administered over 20 seconds into the left anterior descending coronary artery (Fig. 6). In these animals, coronary arterial flow, measured simultaneously from an electromagnetic flowmeter, showed a marked increase during the first 3 minutes after injection, and systolic thickening of the ventricular wall decreased from 18 to $11 \mathrm{~mm}$ during the same time. In other words, end-diastolic thickness decreased, systolic thickening was virtually abolished, and the process of contraction became extended into what is early diastole for the remainder of the ventricle. Yet, at the same time, flow in the left anterior descending coronary artery increased by 40 percent above its control value. None of these changes occurred in animals when the same dose of drug was infused into the pulmonary artery.

Similar findings have been documented in several patients. Data from one of these patients (Fig. 7), measured beat by beat over a period of 300 seconds, clearly show the immediate effect of nifedipine on ventricular wall dimensions, end-diastolic pressure, and
$\mathrm{V}_{\max }$. Perhaps most important, in terms of the mechanism of action of the drug, the relaxation time constant increased by some 50 percent. All of these values could also be reliably measured during a period of voluntary apnea, showing that respiratory influences were minimal. The effects of nifedipine were maximal 30 seconds after injection, at which time the shortening fraction was barely 1.6 percent and $V_{\max }$ was at its lowest, yet coronary sinus blood flow had increased $200 \mathrm{ml} / \mathrm{min}$. These appear to be extremely favorable responses for the ischemic myocardium.

These human and animal experiments complement each other and indicate that there is marked local contractile "arrest" in the presence of increased coronary flow. These data also complement those originally presented by Grün and Fleckenstein ${ }^{13}$ and Vater, ${ }^{14}$ who demonstrated that similar doses of nifedipine led to significant reductions in myocardial oxygen consumption in regions perfused by the coronary artery into which the drug had been injected.

Beneficial effects of nifedipine therapy for unstable angina: This series of observations, indicating an "oxygen-sparing" effect of nifedipine, led to our use of the drug in patients with unstable angina (Fig. 8 and 9 ). Indeed, the hypothesis has been put forward that the subset of patients with suspected coronary arterial spasm may receive no benefit from beta adrenergic blocking agents, and Yasue et al. ${ }^{4}$ have specifically argued against their use in this group of patients. Rather, when beta adrenergic blockade has failed to relieve symptoms-despite its reduction of heart rate and 
SEQUENCE OF EVENTS IN 47 PATIENTS ADMITTED TO THE CCU

WITH UNSTABLE ANGINA IN WHOM IMPENDING INFARCTION WAS SUSPECTED

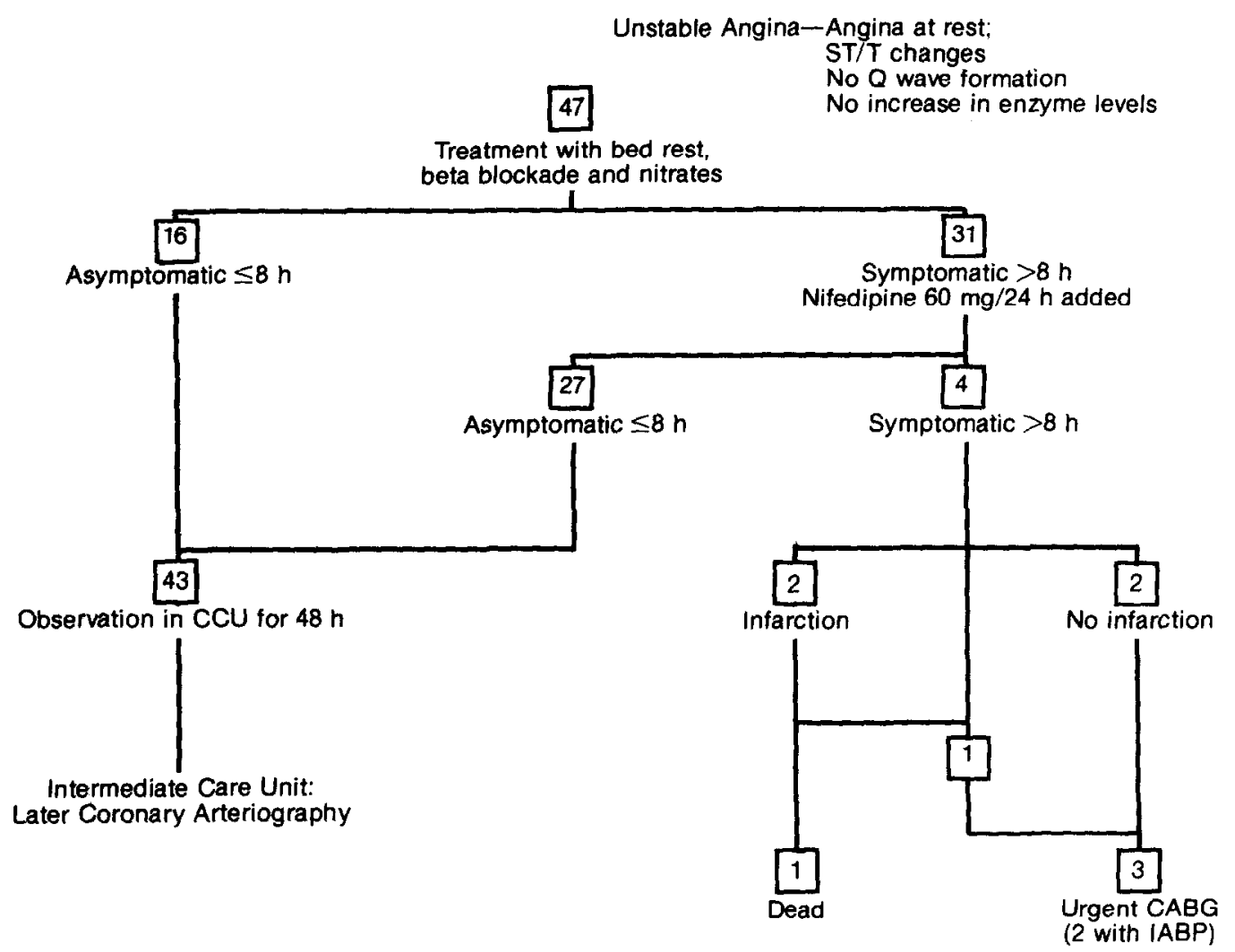

FIGURE 8. Schematic view of developments in 47 patients with suspected impending myocardial infarction. CABG = coronary arterial bypass grafting; $\mathrm{CCU}=$ coronary care unit; IABP = intraaortic balloon pumping.

THE INTERPLAY OF CAUSES OF ANGINA PECTORIS, ARRHYTHMIAS, MYOCARDIAL INFARCTION AND SUDDEN DEATH (ZONE WWID)

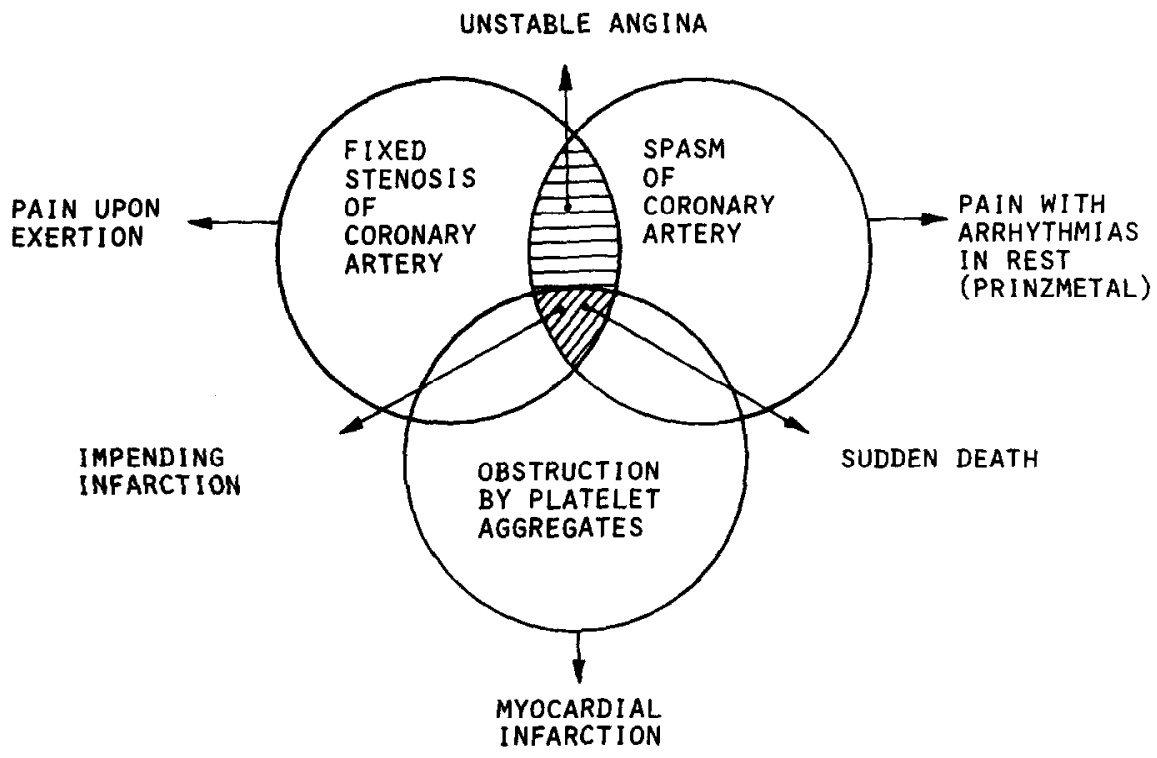

FIGURE 9. Schematic view of the interplay of the three main causes of unstable angina: fixed stenosis of coronary arteries, coronary arterial spasm, and coronary arterial obstruction by platelet aggregates. Nifedipine appears to have its most useful application in the horizontally hatched area. 
competitive blocking at beta receptor sites-the addition of nifedipine, or perhaps the use of nifedipine alone, may be the more logical approach. Theoretically, the inhibition of transmembrane calcium influx into cardiac muscle fibers. results in less phosphate-bound energy being transformed into mechanical work by calciumdependent myofibrillar adenosine triphosphate (ATP), which in turn leads to a reduction in cardiac oxidative metabolism; oxygen need is therefore diminished. In addition, the reduction in the calcium-dependent contractile tone of the larger epicardial coronary arteries-and perhaps to some extent the capillaries as well-indicated by the sudden reduction of ventricular wall thickness (Fig. 6B) leads to increased flow and thus rapidly restores the regional oxygen concentration to normal. In addition to these changes, dilation of large peripheral arteries will diminish afterload and may result in a further, indirect reduction in cardiac oxygen demand.

Henry et al. ${ }^{15}$ have indicated that even when an area around an infarct is rendered ischemic, a reduction in the quantity of ischemic cells can be achieved with nifedipine. In those patients in our group who did not respond to beta adrenergic blockade, nifedipine produced similar dramatic and sudden results. Although this study was not randomized and in many other respects did not meet the requirements of a strict clinical trial, the reduction in symptoms was impressive. Twenty-seven of the 31 patients treated with nifedipine in addition to beta blocking agents became asymptomatic within a very short period of time and remained so in nearly all instances. Given the brittle clinical state of these patients, and the failure of all other supportive therapy, it is highly likely that nifedipine was responsible for the improvement. In fact, in the four patients in whom nifedipine did not evoke a similarly favorable response, the extent of fixed organic stenosis, as demonstrated on coronary arteriography, was severe enough that the lack of response to a spasmolytic agent was hardly surprising. The subsequent response of these patients to intraaortic balloon pumping and emergency bypass surgery underscores that their obstructive lesions were mainly of an organic nature. Under these conditions, the action of nifedipine may well be less specific and unique.

Role of coronary spasm in unstable angina in presence of severe atherosclerotic disease: In this regard it is of interest to examine the coronary arteriographic findings in 20 of the 27 patients who responded promptly to nifedipine and to discuss briefly the rate of myocardial infarction. One patient with postinfarction angina died 7 days after admission to the coronary care unit, just before the planned catheterization. Autopsy showed extensive three vessel disease, including narrowing of the left main coronary artery. As indicated earlier, of the remaining 19 patients, 1 had greater than 90 percent narrowing of the left mainstem, and 9 had three vessel disease, 3 had two vessel disease and 6 had one vessel disease with more than 90 percent obstruction. To date, 15 of these 19 patients have undergone bypass grafting and 4 sustained a nonfatal myocardial infarction before they could be operated on-in immediate relation to the cardiac catheterization procedure in 2 and after discharge from the hospital in 2 . The 15 patients operated on are asymptomatic and no longer receive nifedipine therapy; the 11 patients not operated on are also asymptomatic but still receive nifedipine therapy.

These findings indicate the presence of severe atherosclerotic coronary artery disease in 14 of the $20 \mathrm{pa}-$ tients studied. It is suggested that the symptoms in the remaining 6 patients approximate those of Prinzmetal's syndrome although the complete manifestations thereof could not be observed during the acute phase. Because of the prompt response to nifedipine, spasm would seem to have been the dominant mechanism. In those patients with a long-standing history of coronary artery disease and severe atherosclerotic disease spasm probably played only a secondary role, although it was equally responsive to nifedipine.

Therapeutic failures and occurrence of myocardial infarction: In the four patients who did not respond to nifedipine therapy the rapidity of the subsequent events suggests that treatment with nifedipine had commenced too late. Five of the 27 patients who responded to nifedipine nevertheless sustained an infarction in the subsequent weeks compared with 2 of the 4 nonresponders. Because 1 of the 5 responders had had a previous infarction (group III) and in 2 (both from group II) the infarction occurred during coronary arteriography, nifedipine therapy can be considered to have failed in only 2 ( 7.4 percent) of the 27 patients in the longer term. This incidence relates favorably to the generally quoted incidence of myocardial infarction, which ranges from the 13 percent in the Rotterdam IMIR study 17 to 23 percent reported by Vakil, ${ }^{18}$ in these severely ill patients with impending infarction. Incidentally, in our study the two responders to nifedipine with subsequent infarction had three vessel disease during coronary arteriography.

Therapeutic implications: We believe that nifedipine should be added to beta adrenergic blocking drugs when the latter show no immediate effectiveness in patients presenting with angina at rest. The combination of nifedipine and a beta blocking agent has not been shown to cause any adverse hemodynamic effects. In our opinion, nifedipine deserves further clinical evaluation for use in unstable angina.

Nifedipine inhibits myocardial contractility while increasing coronary blood flow and this combination of actions may help prevent myocardial infarction in patients who have unstable angina with a substantial vasospastic component (Fig. 9). However, those patients with advanced fixed organic obstructions do not respond as well.

\section{Acknowledgment}

The supplies of nifedipine (Adalat $\left.{ }^{(}\right)$used in our study were graciously made available by the Bayer Company, West Germany. 


\section{References}

1. Latham P. Collected Works, Vol. I. London: New Sydenham Society, 1876

2. Maseri A, L'Abbate A, Baroldl G, et al. Coronary vasospasm as a possible cause of myocardial infarction. N Engl J Med 1978; 299:1271-7.

3. Hillis LD, Braunwald E. Coronary-artery spasm. N Engl J Med 1978:299:695-702

4. Yasue H, Touyama M, Shimamoto $M$, of al. Role of autonomic nervous system in the pathogenesis of Prinzmetal's variant form of angina. Circulation 1974;50:534-9.

5. Muller JE, Gunther SJ. Nifedipine therapy for Prinzmetal's angina. Circulation 1978:57:137-9

6. Van Ekelen WAJJ, Robles de Medina EO. Variant forms of angina pectoris. Eur J Cardiol 1978;8:305-17.

7. Curry RC Jr, Peplne CJ, Sabom MB, Conti CR. Similarities of ergonovine-induced and spontaneous attacks of variant angina Circulation 1979:59:307-12

8. Michels MR, Haalebos M, Hagemeljer F, et al. Intra-aortic balloon pumping in myocardial infarction and unstable angina. Eur Heart $J$ 1980:1:31-43.

9. Verdouw PD, Ten Cate FJ, Hugenhoftz PG. Effect of nifedipine on segmental myocardial function in the anesthetized pig. Eur J Pharmacol 1980;63:209-12.

10. Brower RW, ten Katen HJ, Meester GT. Direct method for determining regional myocardial shortening after bypass surgery from radiopaque markers in man. Am J Cardiol 1978;41:1222-9.

11. Meester GT, Zeelenberg C, Gorter S, Miller AC, Hugenholtz PG.
Beat-to-beat analysis of left ventricular function parameters. Eur J Cardiol 1974; 1:279-82

12. Serruys PW, Brower RW, ten Katen HJ, Bom AH, Hugenholtz PG. Regional wall motion from radiopaque markers following intracoronary injection of nifedipine. Circulation, in press.

13. Grün G, Flockenstein A. Die elektromechanische Entkopplung der glatten Gefassmuskulatur als Grundprinzip der Coronardilation durch 4-(2-Nitrophenyl)-2,6-dimethyl-1,4-dihydropyridin-3,5-dicarbonsäure-dimethylester (BAY a 1040, Nifedipine). Arzneim Forsch 1972;22:334-44.

14. Vater $W$. Myocardial oxygen consumption under the influence of nifedipine (Adalat) in the anethetized dog. In: Lochner W. Kroneberg G, ed. New Therapy of Ischemic Heart Disease. Berlin: Springer Verlag, 1975:77.

15. Henry P. Comparative pharmacology of calcium antagonists: nifedipine, verapamil and diltiazem. Am J Cardiol 1980; 46: 1047-58.

16. Booman F, Relber JHC, Gerbrands JJ, Slager CJ, Schuurbiers JCH, Meester GT. Quantitative analysis of coronary occlusions from coronary cine-angiogram. Geneva: Proceedings Computers in Cardiology 1979:177-80.

17. Lubsen J, Does E v/d, Pool J, Hugenholtz PG. Imminent myocardial infarction, Rotterdam. IMIR study. Heart Bull 1976;3:88118.

18. Vakil RJ. Pre-infarction syndrome-management and follow-up Am J Cardiol 1964;14:55-63. 